INTRODUCTION TO DRUG METABOLISM 


\section{INTRODUCTION TO DRUG METABOLISM}

\section{G. Gordon Gibson, PhD}

Lecturer in Pharmacological Biochemistry University of Surrey

AND

Paul Skett, Fil. dr. Lecturer in Pharmacology University of Glasgow

Springer-Science+Business Media, B.V. 
(C) 1986 G. G. Gibson and P. Skett

Originally published by Chapman and Hall in 1986.

Softcover reprint of the hardcover 1st edition 1986

ISBN 978-0-412-26390-3 ISBN 978-1-4899-3188-7 (eBook)

DOI 10.1007/978-1-4899-3188-7

This title is available in both hardbound and paperback editions. The paperback edition is sold subject to the condition that it shall not, by way of trade or otherwise, be lent, resold, hired out, or otherwise circulated without the publisher's prior consent in any form of binding or cover other than that in which it is published and without a similar condition including this condition being imposed on the subsequent purchaser.

All rights reserved. No part of this book may be reprinted, or reproduced or utilized in any form or by an electronic, mechanical or other means, now known or hereafter invented, including photocopying and recording, or in any information storage and retrieval system, without permission in writing from the publisher.

\section{British Library Cataloguing in Publication Data}

Gibson, G. G.

Introduction to drug metabolism.

1. Drugs-Metabolism

I. Title II. Skett, $P$. $615^{\prime} .7 \quad \mathrm{RM} 301.55$

Library of Congress Cataloging in Publication Data

Gibson, G. Gordon.

Introduction to drug metabolism.

Includes bibliographies and index.

1.. Drugs-Metabolism. I. Skett, Paul. II. Title. [DNLM: 1. Drugs-metabolism. QV 38 G448i] $\begin{array}{llll}\text { RM301.55.G53 } & 1986 & 615.7 & 85-15181\end{array}$ 


\section{Contents}

\section{Preface}

1 Pathways of drug metabolism 1

1.1 Introduction 1

1.2 Phase I metabolism 2

1.3 Phase II metabolism $\quad 15$

1.4 Phase III metabolism 26

1.5 Endogenous metabolism related to drug metabolism 27

$\begin{array}{lll}1.6 & \text { General summary } & 37\end{array}$

$\begin{array}{lll}1.7 & \text { Further reading } & 37\end{array}$

2 Enzymology and molecular mechanisms of drug metabolism 39

2.1 Introduction 39

2.2 Cytochrome P-450-dependent mixed-function oxidation reactions 42

2.3 Microsomal flavin-containing monooxygenase 52

2.4 Prostaglandin synthetase-dependent co-oxidation of drugs 54

2.5 Reductive drug metabolism $\quad 56$

2.6 Epoxide hydrolase $\quad 60$

2.7 Glucuronide conjugation reactions 63

2.8 Glutathione-S-transferase $\quad 66$

2.9 Sulfate conjugation 69 
vi Introduction to Drug Metabolism

2.10 Amino acid conjugation 70

2.11 Control and interactions of drug metabolism pathways 71

$\begin{array}{ll}2.12 \text { Further reading } & 79\end{array}$

3 Induction and inhibition of drug metabolism $\quad 82$

$\begin{array}{lll}3.1 & \text { Introduction } & 82\end{array}$

3.2 Induction of drug metabolism 83

3.3 Inhibition of drug metabolism 100

3.4 Conclusions 108

3.5 Further reading 110

$4 \quad$ Factors affecting drug metabolism: internal factors 113

4.1 Introduction 113

4.2 Species differences 114

4.3 Genetic differences 117

4.4 Sex differences 121

4.5 Age differences 124

4.6 Hormonal control of drug metabolism 132

$\begin{array}{ll}4.7 & \text { Effects of disease on drug metabolism } \\ & 139\end{array}$

5 Factors affecting drug metabolism: external factors 147

5.1 Dietary factors 148

5.2 Environmental factors 162

5.3 Relative importance of physiological and environmental factors in determining drug-metabolizing capacity in the human $\begin{array}{lr}\text { population } & 169\end{array}$

$\begin{array}{lll}5.4 \text { Further reading } & 171\end{array}$

6 Pharmacological and toxicological aspects of drug metabolism 175

$\begin{array}{lll}6.1 & \text { Introduction } & 175\end{array}$

6.2 Pharmacological aspects of drug metabolism 176

6.3 Toxicological aspects of xenobiotic metabolism 185

6.4 Balance of toxifying and detoxifying pathways 190

$\begin{array}{ll}6.5 \text { Conclusions } & 194\end{array}$

$\begin{array}{ll}6.6 & \text { Further reading } \\ & 195\end{array}$

7 Pharmacokinetics and the clinical relevance of drug metabolism 199

$\begin{array}{lll}7.1 & \text { Introduction } & 199\end{array}$

$\begin{array}{lll}7.2 & \text { Pharmacokinetics } & 200\end{array}$

7.3 Methods for studying drug metabolism in Man 210

7.4 Clinical relevance of drug metabolism 222 
Contents vii

7.5 Summary

236

7.6 Further reading

236

8 Techniques and experiments illustrating drug metabolism

239

8.1 Introduction

239

8.2 In vitro assays for drug-metabolizing enzymes 240

8.3 Factors affecting drug metabolism

264

8.4 Induction and inhibition of drug metabolism and a correlation of in vivo drug action with in vitro hepatic drug-metabolizing activity

8.5 Urinary excretion of paracetamol in Man 276

8.6 Problems 281

8.7 Further reading and references 281

$\begin{array}{ll}\text { Index } & 285\end{array}$ 


\section{Preface}

Although the scientific literature on drug metabolism is extensive, it suffers from the disadvantage that the material is diffuse and consists largely of specialist monographs dealing with particular aspects of the subject. In addition, although there are a few excellent texts on drug metabolism in print, these tend to be earlier publications and hence do not take into account the many recent advances in this area. Our motivations for writing this book therefore arose from the clear need for a recent and cohesive introductory text on this subject, specifically designed to cater for the needs of undergraduate and postgraduate students. Much of the subject matter in this text is derived from various courses on drug metabolism given at the University of Surrey and the University of Glasgow to basic science students in pharmacology, biochemistry, nutrition and nursing studies, to pre-clinical medical students and to undergraduate and post-graduate students in toxicology. Therefore, it is our intention that this text will serve as a primer in drug metabolism to a variety of students in the life sciences taking courses in this subject.

The term 'drug metabolism' in its broadest sense may be considered as the absorption, distribution, biotransformation and excretion of drugs. To cover all these facets of drug metabolism in a single text is a voluminous task and therefore we have focused primarily on the biotransformation aspects of the subject. Having said this, the text is not solely a list of drug metabolism pathways, but rather it uses biotransformation reactions to rationalize many 
pharmacological and toxicological manifestations of drug action, clearly an important consideration in the clinical use of drugs.

The subject of drug metabolism or drug biotransformation is introduced in Chapter 1 by considering the relevant pathways, i.e. the enzyme-catalysed changes in drug structure. Wherever possible, currently used drugs are given as examples. Consideration is also given to the classification and functional role of the enzymes involved in these pathways. This is of importance as many of the drug-metabolizing enzymes are also involved in the metabolism of endogenous compounds and the chapter concludes by drawing attention to the competition between endogenous and exogenous substrates of these enzymes. Chapter 2 continues on the enzyme theme and considers, in detail, the enzymology of drug metabolism reactions including the molecular mechanisms involved. This chapter concludes by considering drug metabolism pathways not as separate events, but rather from the viewpoint of the interaction of the various pathways both with each other and with the pathways of endogenous, intermediary metabolism. Detailed consideration is also given to the overall control and regulation of drug metabolism pathways from various levels of integration.

Having established the basic chemistry and enzymology of drug metabolism, the three following chapters $(3,4$ and 5$)$ discuss factors that modulate drug metabolism, including induction and inhibition and external and internal factors. These are important aspects of any consideration of drug metabolism as the enzymes catalysing the various reactions are susceptible to changes in their activity or concentration, and are particularly influenced by other drugs or chemicals. Accordingly, these chapters are designed to rationalize, on an enzymatic or molecular level, why certain drugs, when given in combination, result in a response that could not be easily predicted by considering each drug in isolation. In view of the widespread use of polypharmacy where several drugs are given simultaneously, it is clear that the student should not only be aware of potential drug-drug interactions but should also be able to rationalize and explain why combination drug therapy interactions occur. These chapters conclude with a consideration of some of the internal or physiological factors that influence or regulate drug metabolism. A knowledge of these physiological factors is of utmost importance in clinical pharmacology in that, depending on the age, sex, hormonal status or genetic background of the patient, drug biotransformation pathways may either be switched on or turned off, thus influencing the clinical usage of drugs. In addition, patients on drug therapy for a particular ailment may have additional disorders of the heart, liver or kidney systems, defects which may subsequently influence drug disposition in the original disease, and attention is therefore drawn to the role of disease states in drug metabolism.

No matter how extensive or informative a test in drug metabolism is at the 
basic or theoretical level, a major consideration of this subject must include the the raison d'etre of drug biotransformation pathways. For example, the earlier chapters in this text highlight that one of the roles of drug metabolism is to make lipid-soluble drugs more polar, hence more readily excreted from the body. Thus if an efficient 'removal mechanism' did not exist for drugs, these highly lipid-soluble drugs would remain in the body for long time periods. Providing that the retained drug was maintained at sufficiently high concentrations at its site of action, then a prolonged pharmacological response would result. The majority of drugs have a half-life of only several hours in man and do not, in general, persist in the body; this underlines the important role of drug metabolism in clearing drugs from the body and hence terminating the pharmacological response. However, it should be emphasized that drug metabolism has additional, equally important roles to play in the overall, biological response to drugs. For example, as considered in Chapter 6, drug biotransformation may result in changes in both pharmacological and toxicological responses to drugs, an important consideration in drug therapy. From the pharmacological viewpoint, many drugs are inactivated by drug metabolism, probably as a result of the chemically changed drug metabolite not being recognized by the appropriate receptor system. Conversely, many 'pro-drugs' are inactive per se, and absolutely require biotransformation to release the pharmacologically active drug. Drug metabolism also has an important role to play in the side effects or toxicity of drugs. There are many well-documented examples where drug metabolism results in the transformation of a totally innocuous drug to a metabolite that is highly biologically reactive, and by a variety of mechanisms, can result in an overt toxicological response. Therefore in Chapter 6, we have emphasized that drug metabolism not only facilitates drug excretion, but is also an important determinant of pharmacological and toxicological responses to drugs.

One of the goals in the study of drug metabolism is to understand biotransformation pathways and biological responses to drugs in man. Unfortunately, there are many obvious practical and ethical constraints limiting our study of drug metabolism in man. Chapter 7 deals primarily with in vivo drug metabolism in man, and draws attention to the problems and advantages of applying in vitro drug metabolism data to man. Emphasis is placed on pharmacokinetics and the clinical relevance of drug metabolism in the human situation, drawing on the knowledge and information built up from previous chapters. Pharmacokinetics is not exclusively considered from a mathematical viewpoint but rather from a physiological/clinical stance. In this way, it is our intention to highlight the importance of pharmacokinetics in drug action, without placing an undue demand on the student to struggle with unnecessary mathematical formulae.

The final chapter in this text is concerned with the more practical aspects of drug metabolism and outlines several experiments that may be undertaken by 
practical classes. This chapter should not be considered in isolation but rather is designed to demonstrate experimentally some of the concepts developed in the remainder of the text. Rigid experimental practicals are not extensively described and we have devised this chapter on a 'menu' basis. This was achieved by initially detailing the methodology associated with the study of the enzymes and metabolites of drug biotransformation pathways, and subsequently applying these methodologies to highlight some concepts in drug metabolism. In this manner, the organisers of class practicals can devise their own experiments, tailored to their own needs and constraints placed upon them by factors such as class size and availability of facilities (including instrumentation). This chapter should also be of use to postgraduate students who require a detailed laboratory manual of experimental techniques to assay both the content and functional expression of the drug-metabolizing enzymes. The detailed methodology, analytical techniques and class practicals described in this chapter are based on both our own research activities and experience of undergraduate and postgraduate practical classes; and it should be emphasized that these have successfully run in our laboratories for several years.

In compiling this text, we have made liberal use of both tables and figures. We feel this is an important aspect of an introductory text of this nature in that a concept is more readily appreciated and remembered if numerical data or a simple figure can exemplify the point being made. In addition, we have included an extensive further reading section at the end of each chapter. Where possible, we have included all the text books, monographs and symposium proceedings relevant to each chapter, in addition to recent review articles. Where necessary, we have also included references to original articles to highlight a particular point being made in the chapter. In this way, we hope we have provided reference to sufficient additional reading material such that the interested reader can further pursue any particular area of interest in drug metabolism and related subjects.

\section{Acknowledgements}

In producing this text, the authors would like to acknowledge the expert secretarial assistance of Mrs Valerie Saunders and Mrs Marjory Wright in typing the initial drafts. We would also like to thank our present and past students who made so many constructive suggestions as to the content and emphasis of this book. Their help was indispensable and hopefully has helped us to identify the focus of this text. We also wish to thank both our colleagues and associates in the publishing area for their advice and permission to use some of their published material. Finally, we express our thanks to the staff of Chapman and Hall for their excellent co-operation and for giving us the opportunity to bring this project to fruition. 